\title{
Efficacy and tolerability of milnacipran and escitalopram: a comparative study among patients of depression
}

\author{
Meghna Shinde, Pooja Reddy*, Mohit Kulmi, Chhaya Goyal
}

Department of Pharmacology, Sri Aurobindo Institute of Medical Sciences, Indore, Madhya Uttar Pradesh, India

Received: 30 March 2018

Revised: 06 April 2018

Accepted: 10 April 2018

*Correspondence to:

Dr. Pooja Reddy,

Email: drpoojasreddy@ gmail.com

Copyright: (C) the author(s), publisher and licensee Medip Academy. This is an openaccess article distributed under the terms of the Creative Commons Attribution NonCommercial License, which permits unrestricted noncommercial use, distribution, and reproduction in any medium, provided the original work is properly cited.

\begin{abstract}
Background: The present prospective, open labelled study was designed to evaluate the efficacy and tolerability of escitalopram, selective serotonin reuptake inhibitors (SSRI) in comparison with milnacipran, dual serotonin and noradrenaline reuptake inhibitors (SNRI) in the treatment of major depressive disorder.

Methods: Outpatients $(\mathrm{N}=120)$ with an ongoing/newly diagnosed ICD-10 major depressive episode and having a minimum score of 8 on the 21-item Hamilton Depression Rating Scale (HDRS) were assigned to escitalopram, 10-20 mg/day (54 patients) and milnacipran 50-100mg (66 patients), for an 8 week treatment period with follow up at 2 nd, 4 th and 8 th week. The parameters for efficacy were improvement (decrease in HDRS scores at 8 weeks from baseline values), response (decrease of $\geq 50 \%$ in the HDRS scores) and remission (HDRS score of $\leq 7)$. Tolerability was assessed by comparing the frequency of adverse effects and drop out rate due to the same at the end of $2 \mathrm{nd}$, 4th and 8 th week in both the groups.

Results: Improvement, Response rate and Remission rates at the end of eight weeks were $71.11 \%, 83.33 \%$ and $58.33 \%$ for escitalopram and $59.35 \%, 34.14 \%$ and $75.6 \%$ for milnacipran respectively. Adverse experiences were reported by $14 \%$ of patients in escitalopram group and $79.2 \%$ patients in milnacipran group at 8 weeks. Additionally, there were significantly lesser dropouts due to adverse events in escitalopram $(3.70 \%)$ than in milnacipran group $(30 \%)$.

Conclusions: Escitalopram, the Senantiomer of citalopram, is a safe and effective antidepressant with potentially superior tolerability and comparable efficacy to the dual reuptake inhibitor, Milnacipran.
\end{abstract}

Keywords: Escitalopram, HDRS, Milnacipran, SSRI, SNRI

\section{INTRODUCTION}

Depression is designated as the "common cold" of psychiatric illness as it is frequently encountered in clinical practice. But unlike common cold, the outcome of untreated depression is grave, ranging from economic losses due to work impairment to increased suicidality. According to WHO, depression is one of the world's most disabling diseases, affecting nearly 340 million people worldwide. ${ }^{1}$ The incidence of depression has risen every year since the early $20^{\text {th }}$ century and it is estimated to become the second largest cause of disease or disability worldwide by the year $2020 .^{2}$ Timely recognition of symptoms of depression and its treatment is very important as it is associated with the risk of suicide.

The major symptoms of depression like depressed mood , anhedonia, changes in sleep and appetite, feeling of worthlessness, psychomotor retardation etc have been attributed to deficiency of amine neurotransmitters mainly serotonin (5HT) and norepinephrine (NE) in the brain. ${ }^{3}$ There are various treatment options like psychotherapy and somatic therapies (e.g. ECT, light therapy) but 
Antidepressants have emerged as the mainstay in the treatment of depression. ${ }^{4}$ They act by blocking the transporter responsible for reuptake of serotonin and norepinephrine and thus increase the concentration of the one or both the neurotransmitters at post synaptic receptors.

The market of antidepressants has flourished since the development of tricyclic antidepressants (TCAs) and monoamine oxidase inhibitors (MAOIs) in mid-1950's. They were clinically efficacious antidepressants but were associated with unwanted adverse effects because of multiple receptor interactions. The discovery of selective serotonin reuptake inhibitors (SSRIs) (fluoxetine, fluvoxamine, paroxetine, sertraline, citalopram, escitalopram) revolutionized the treatment of depression and gained popularity due to their comparable efficacy and favourable tolerability than the older compounds. After that dual noradrenaline and serotonin reuptake inhibitors (SNRIs) (milnacipran, venlafaxine, duloxetine), selective noradrenaline (e.g. reboxetine) and other atypical antidepressants were developed. ${ }^{5}$

Escitalopram is the most selective serotonin reuptake inhibitors being commonly used in psychiatry OPD for the treatment of depression. In previous studies, Escitalopram has shown comparable or superior efficacy and better tolerability compared to other SSRI's. ${ }^{6-10}$ It was also found to be non inferior and significantly better tolerated than the two SNRIs, Venlafexine and Duloxetine. ${ }^{11-13}$ Milnacipran is the most balanced SNRI which blocks the reuptake of both serotonin and norepinephrine equally. ${ }^{14}$ Further, the antidepressant efficacy and tolerability have been shown to be comparable or superior to comparators, such as selective serotonin reuptake inhibitors (fluoxetine, fluvoxamine, paroxetine), a serotonin-norepinephrine reuptake inhibitor (venlafaxine), and tricyclic antidepressants (amitriptyline, imipramine). ${ }^{15-19}$

This study was planned to compare the efficacy and tolerability of the gold standard SSRI escitalopram with milnacipran, a newer SNRI, in patients of depression as no such study has been done to the best of our knowledge.

\section{METHODS}

The present study was a prospective, open-labelled, comparative, efficacy- tolerability type of study. The duration of our study was 8 weeks (60 days). Patients attending the outpatient clinic of a tertiary-care teaching hospital were selected for the study. Men and women between the ages of 18 and 60 years, fulfilling the ICD-10 criteria for major depression, and having a minimum score of 8 on the 21-item Hamilton Depression Rating Scale (HDRS) and 3 on the clinical global impression (CGI) scale were included in the study. Patients who had been administered a clinically effective dose of drugs known to affect mood or other somatic symptoms in the preceding 2 weeks, depression secondary to some underlying disease, those with concurrent medical or co-morbid psychiatric illness (including substance abuse) and bipolar symptoms were excluded from the study. The study was approved by Institutional Ethics Committee. The patients who agreed to give their written informed consent were included in the study. They were assessed for efficacy and tolerability at $2^{\text {nd }}$ week, $4^{\text {th }}$ week and $8^{\text {th }}$ week of starting treatment. The efficacy was assessed in terms of magnitude of improvement as shown by decrease in HDRS scores (21 score Hamilton Depression Rating Scale) and CGI scale at 8 weeks from baseline values, response to the drugs, which was defined by a decrease of $\geq 50 \%$ in the HDRS scores and remission, which was defined as the HDRS score of $\leq 7$.

Tolerability was assessed by recording and comparing the frequency of adverse effects and dropout rate due to adverse events at the end of $2^{\text {nd }}$ week, $4^{\text {th }}$ week and $8^{\text {th }}$ week.

\section{RESULTS}

Of the 120 patients enrolled in the study, 54 patients received Escitalopram 10-20 $\mathrm{mg}$ (Group A) and 66 patients received Milnacipran 50-100 mg (Group B). 48 patients from Group A and 41 patients from Group B completed the study. A total of 31 patients from both the groups, dropped out and were excluded from the study.

The sociodemographic data of both the groups revealed that the majority of patients were in the age group of 3140 years (average 33.27 years), females (64\%), married $(67 \%)$, educated up to matriculation $(67 \%)$, and are of urban background $(56.2 \%)$ and had very severe $(32.60 \%)$ type of depression.

\section{Efficacy}

Improvement

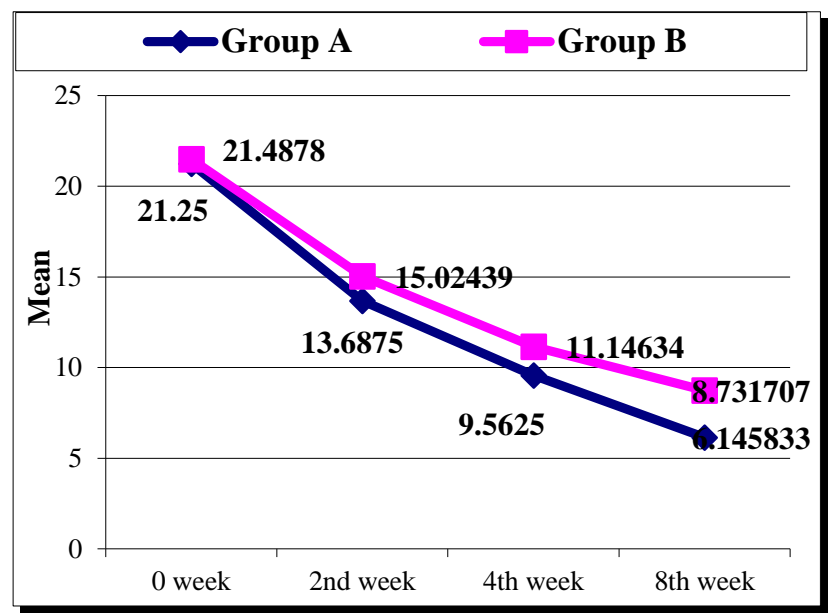

Figure 1: Mean hamilton depression rating Scale Score per visit.

In the 'treatment completers', there was a steady decrease in depression rating in both the treatment groups, with the 
mean total score falling from $21.25( \pm)(\mathrm{SD} \pm 7.04)$ at baseline to $6.14(\mathrm{SD} \pm 3.14)$ at the end of 8 weeks in the escitalopram group, and from 21.48(SD \pm 7.345$)$. to 8.73 $(\mathrm{SD} \pm 4.52)$ in the milnacipran group. Thus, the total change in HDRS score from baseline in Group A (Escitalopram) was 15.11 exhibiting a total improvement of $71.11 \%$ and in Group B was 12.75 exhibiting a total improvement of $59.35 \%$.

The change in both the groups from the baseline to the end of week 8 was statistically significant $(p<0.001)$ confirming antidepressant action of both the drugs. Escitalopram produced significantly greater improvement in HDRS scores from baseline than Milnacipran on $60^{\text {th }}$ day $(\mathrm{p}$ value $=0.002)($ Figure 1$)$.

\section{Response}

$83.33 \%$ of patients belonging to the escitalopram group and $75.6 \%$ in the milnacipran group were responders on the HDRS. The overall response rate of Escitalopram and Milnacipran was comparable, with no statistically significant difference between the two groups. ( $p$ value $=0.34)$ (Figure 2).

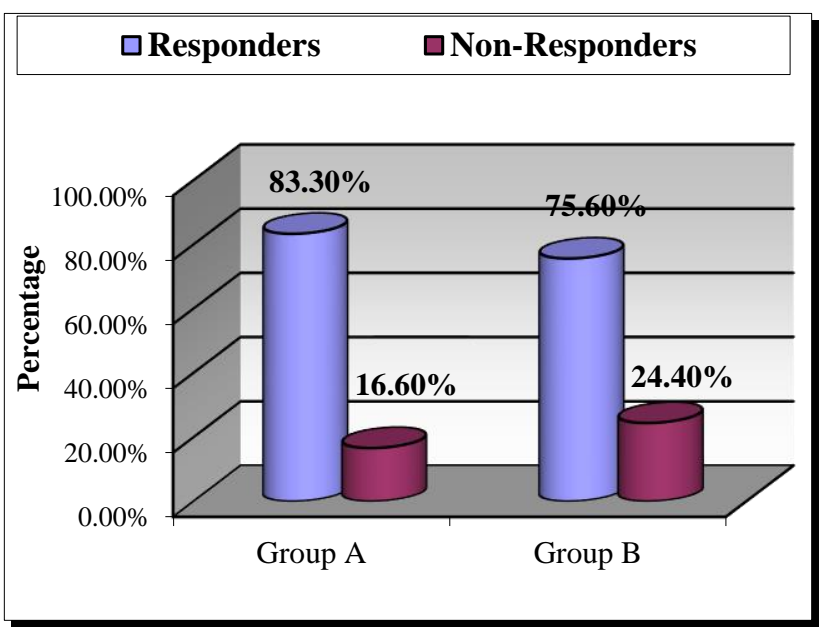

Figure 2: Percentage of responders in Group A (Escitalopram) and Group B (Milnacipran).

\section{Remission}

Remission was significantly greater in Escitalopram treated patients $(58.33 \%)$ as compared to that in Milnacipran treated group $(34.14 \%) \quad(p$ value $=0.02)$ (Figure 3).

\section{Tolerability}

Escitalopram appears to be better tolerated than milnacipran. Drop out rate due to adverse events was significantly greater in Milnacipran group (30\%) as compared to Escitalopram group $(3.70 \%)$ (p value $=0.01$ ) Thus suggesting poor tolerability of Milnacipran as compared to Escitalopram.
The frequency of adverse events in Milnacipran group was $90 \%, 87.7 \%$ and $79.2 \%$ at $2^{\text {nd }}, 4^{\text {th }}, 8^{\text {th }}$ week of assessment whereas the frequency of adverse events in Escitalopram group was $74 \%, 22 \%$ and $14 \%$ at $2^{\text {nd }}, 4^{\text {th }}, 8^{\text {th }}$ week of assessment. Nausea was more common in Escitalopram Group whereas Dysuria was the most common side effect seen in Milnacipran Group (Figure 4, Figure 5).

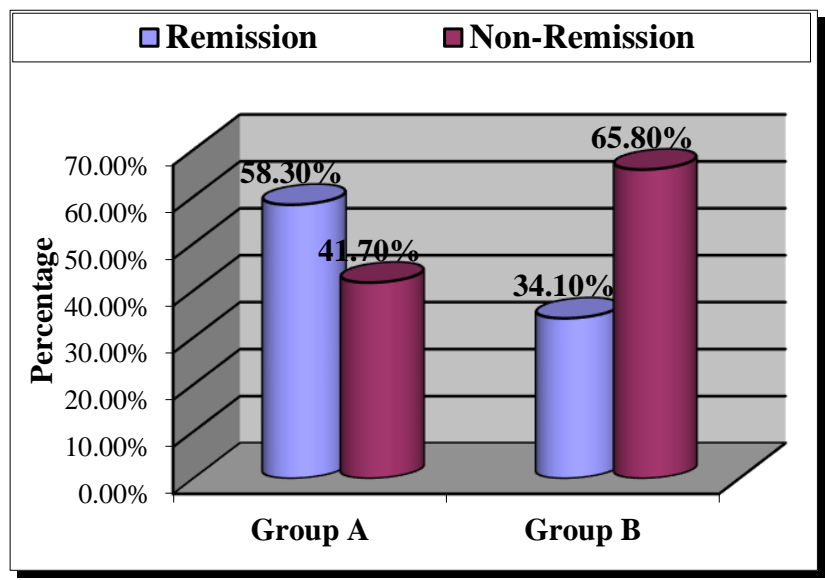

Figure 3: Remission in group A (escitalopram) and group B (milnacipran).

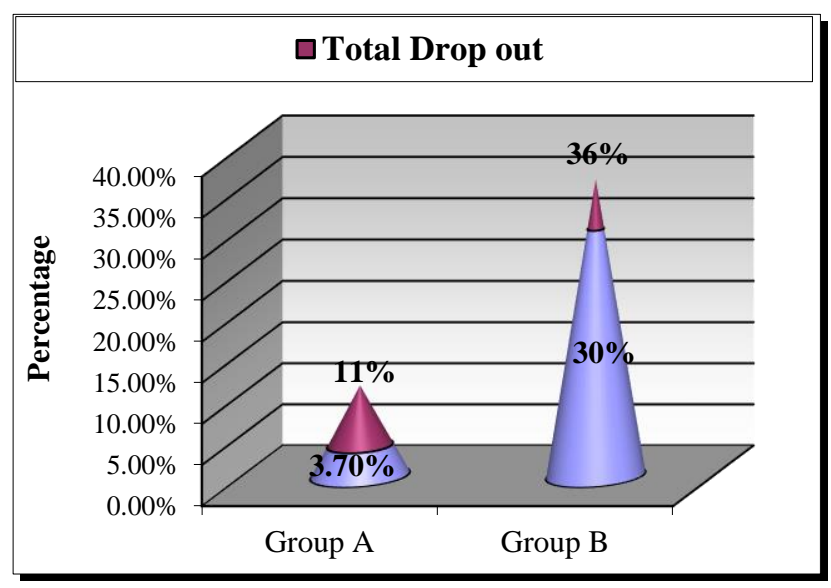

Figure 4: drop out rate due to adverse events.

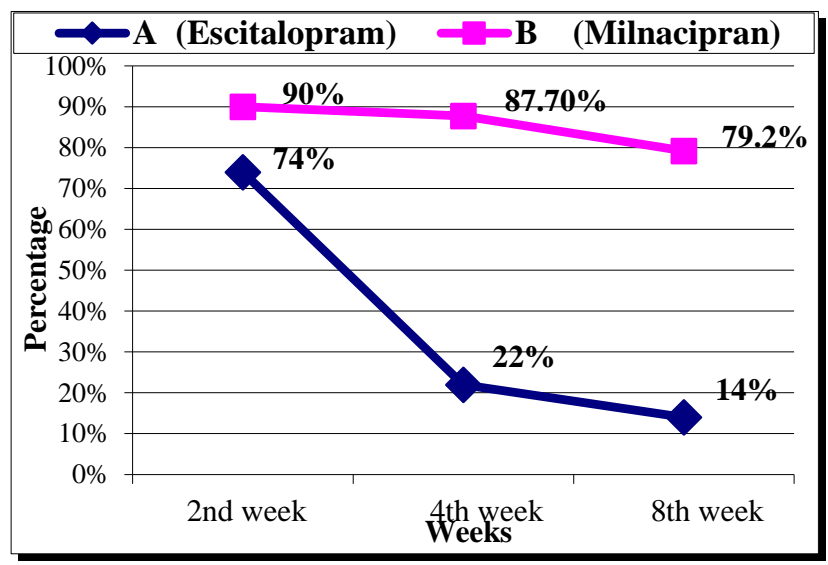

Figure 5: Adverse events reported by the patients at $2^{\text {nd }}, 4^{\text {th }}$ and $8^{\text {th }}$ week 


\section{DISCUSSION}

This study compares the efficacy and tolerability of escitalopram with that of milnacipran in the treatment of major depressive disorder in patients of a tertiary care hospital. Hamilton Depression Rating Scale was selected for gauging efficacy. The drugs were found to have comparable efficacy as measured by the HDRS. Studies comparing the efficacy of escitalopram with that of other SNRIs such as Venlafexine and Duloxetine have reported similar results. ${ }^{11,12}$

Although the response in both the groups was comparable, there was significantly greater improvement on HDRS from baseline at $8^{\text {th }}$ week which coincides with significantly greater number of remitters in the Escitalopram treated group as compared to Milnacipran group. This difference in improvement and remission can probably be attributed to better tolerability of escitalopram so that most of the patients managed to continue the treatment for the entire study period.

The greater degree of improvement in both the drugs was seen in the first visit with a downhill trend observed at each follow up. Also, greater response and remission rates were observed in patients with severe degrees of depression in both the groups.

While considering the tolerability of the two drugs in this study, it was observed that Escitalopram was better tolerated with a lower frequency of side effects and attrition rates. The frequency of adverse event in Group A (Escitalopram) was 74\% which was less than that in Group B (Milnacipran) of $90 \%$. These values are comparable to that found in earlier studies. ${ }^{20}$ Most of the side effects with Escitalopram were mild and temporary and resolved with time during the course of treatment. ${ }^{21}$ Nausea (19\%) which was reported more by the patients in Escitalopram group, and also all the side effects like dry mouth, vomiting, diarrhoea, constipation, headache, fatigue and abdominal pain complained initially by the patients, disappeared completely or reduced in frequency at the end of $4^{\text {th }}$ or $8^{\text {th }}$ week of assessment. ${ }^{15}$ Only ejaculatory dysfunction persisted with same frequency $(6 \%)$ throughout the course of treatment with Escitalopram. Escitalopram is a highly selective inhibitor of membrane associated serotonin transporter SERT and lacks anticholinergic, alpha adrenergic blocking action, seizure or arrhythmia precipitating propensity. This might account for its greater tolerability and fewer side-effects.

The frequency and the variety of adverse effects was more in the Milnacipran group. Being an SNRI, the side effect profile of Milnacipran was different from that of Escitalopram, the most common and troublesome side effect being Dysuria, probably related to increased noradrenergic stimulation of the urinary tract by Milnacipran. ${ }^{20}$ The percentage of patients experiencing dysuria with Milnacipran in this study was significantly greater than that observed in previous studies. ${ }^{15}$ The reason might be the poor tolerability and greater susceptibility of Indian patients to dysuria by Milnacipran. Also most of the side effects like dysuria, constipation, hot flushes and hyperhidrosis showed an uphill course with Milnacipran treatment.

This also accounted for significantly larger dropout rates in the Milnacipran group $(30 \%)$ as compared to that in Escitalopram group $(3.7 \%)(\mathrm{p}<0.05)$. The overall dropout rate of Escitalopram and milnacipran is comparable to that found in earlier studies. ${ }^{15,22}$ Escitalopram clearly edges out as the safe and well tolerated antidepressant than Milnacipran.

Thus, the newer class of SSRIs like Escitalopram can be as effective or even more effective than dual reuptake inhibitors, the SNRIs like Milnacipran and can even be better tolerated. Finally, based on the findings in this study, it can be concluded that Escitalopram is a safe, effective and mainstay drug for the management of depressive disorders and will probably enjoy the same status in the coming years.

Funding: No funding sources

Conflict of interest: None declared

Ethical approval: The study was approved by the Institutional Ethics Committee

\section{REFERENCES}

1. Murray CJL, Lopez AD, eds. The Global Burden of Disease. Cambridge, Mass: Harvard University Press. 1996.

2. Reddy MS. Depression: The disorder and the Burden. Indian Journal of Psychological Medicine 2010 JanJun; 32(1):1-2.

3. Charles De Battista, Katzung BG, Trevor AG. Antidepressant drugs; Basic and Clinical Pharmacology. 11 ${ }^{\text {th }}$ Ed. McGraw Hill; 2009:510-516, 518.

4. Hollon SD, Thase ME, Markowitz JC. Treatment and prevention of depression. Psychological Science in the Public Interest. 2002;3(2):39-77.

5. Pacher P, Kecskemeti V. Trends in the Development of New Antidepressants. Is there a Light at the End of the Tunnel? Curr Med Chem. 2004 Apr;11(7):925-43.

6. Ou JJ, Xun GL, Wu RR, Li LH, Fang MS, Zhang HG, et al. Efficacy and safety of escitalopram versus citalopram in major depressive disorder: a 6-week, multicenter, randomized, double-blind, flexible-dose study. Psychopharmacology. 2011 Feb 1;213(23):639-46.

7. Yevtushenko VY, Belous AI, Yevtushenko YG, Gusinin SE, Buzik OJ, Agibalova TV. Efficacy and tolerability of escitalopram versus citalopram in major depressive disorder: a 6-week, multicenter, prospective, randomized, double-blind, activecontrolled study in adult outpatients. Clin Ther. 2007;29(11):2319-32. 
8. Montgomery S, Hansen T, Kasper S. Efficacy of escitalopram compared to citalopram: a meta-analysis. Int J Neuropsychopharmacol. 2011;14(2):261-8.

9. Ventura D, Armstrong EP, Skrepnek GH, Haim Erder M. Escitalopram versus sertraline in the treatment of major depressive disorder: a randomized clinical trial. Curr Med Res Opin. 2007;23(2):245-50.

10. Kennedy SH, Andersen HF, Thase ME. Escitalopram in the treatment of major depressive disorder: a metaanalysis. Curr Med Res Opin. 2009;25(1):161-75.

11. Khan A, Bose A, Alexopoulos GS, Gommoll C, Li D, Gandhi C. Double-blind comparison of escitalopram and duloxetine in the acute treatment of major depressive disorder. Clin Drug Investig. 2007;27(7):481-92.

12. Bielski RJ, Ventura D, Chang CC. A double-blind comparison of escitalopram and venlafaxine extended release in the treatment of major depressive disorder. J Clin Psychiatry. 2004;65(9):1190-6.

13. Montgomery SA, Huusom AK, Bothmer J. A randomised study comparing escitalopram with venlafaxine $\mathrm{XR}$ in primary care patients with major depressive disorder. Neuropsychobiology. 2004;50(1):57-64.

14. Kasper S, Pail G. Milnacipran: a unique antidepressant? Neuropsychiatric Disease and Treatment. 2010;6(I)23.

15. Lopez-Ibor J, Guelfi JD, Pletan Y, Tournoux A, Prost JF. Milnacipran and selective serotonin reuptake inhibitors in major depression. Clin Psychopharmacol. 1996;11(4):41-6.

16. Sechter D, Vandel P, Weiller E, Pezous N, Cabanac F, Tournoux A. A comparative study of milnacipran and paroxetine in outpatients with major depression. Journal of affective disorders. 2004 Dec;83(2):233-6.
17. Olié JP, Gourion D, Montagne A, Rostin M, Poirier MF. Milnacipran and venlafaxine at flexible doses (up to $200 \mathrm{mg} /$ day) in the outpatient treatment of adults with moderate-to-severe major depressive disorder: a 24-week randomized, double-blind exploratory study. Neuropsychiatr Dis Treat. 2010;6:71-9.

18. von Frenckell R, Ansseau M, Serre C, Sutet P. Pooling two controlled comparisons of milnacipran (F2207) and amitriptyline in endogenous inpatients. A new approach in dose ranging studies. Int Clin Psychopharmacol. 1990;5:49-56.

19. Van Amerongen AP, Ferrey G, Tournoux A. A randomised, double-blind comparison of milnacipran and imipramine in the treatment of depression. $\mathrm{J}$ Affect Disord. 2002;72:21-31.

20. Briley M, Moret C. Antidepressant properties of Specific serotonin-noradrenaline reuptake inhibitors. Antidepressants: New Pharmacological Strategies. 1997;2:45

21. Product Monograph-Issue 8-June 2009. Copenhagen: H. Lundbeck A/S; 2009. Cipralex ${ }^{\circledR} /$ Lexapro ${ }^{\circledR}$ (escitalopram)

22. Colonna L, Andersen HF, Reines EH. A randomized, double-blind, 24-week study of escitalopram $(10 \mathrm{mg} /$ day $)$ versus citalopram $(20 \mathrm{mg} /$ day $)$ in primary care patients with major depressive disorder. Curr Med Res Opin. 2005;21:1659-68.

Cite this article as: Shinde M, Reddy P, Kulmi M, Goyal C. Efficacy and tolerability of milnacipran and escitalopram: a comparative study among patients of depression. Int J Basic Clin Pharmacol 2018;7:83943. 